\title{
The influence of formation conditions on the growth and morphology of carbon trees
}

\author{
Hai-Long Ma ${ }^{\text {a,c }}$, Dang Sheng Su ${ }^{\text {b }}$, Guo-Qiang Jin ${ }^{\text {a }}$, Xiang-Yun Guo ${ }^{\text {a,* }}$ \\ ${ }^{a}$ Key Laboratory of Carbon Materials, Institute of Coal Chemistry, CAS, \\ Taiyuan P.O. Box 165, Taiyuan, Shanxi Province 030001, China \\ ${ }^{b}$ Department of Inorganic Chemistry, Fritz-Haber-Institute of MPG, Berlin 14195, Germany \\ ${ }^{\mathrm{c}}$ Graduate School of the Chinese Academy of Sciences, Beijing 100039, China \\ * Corresponding author. Fax: +86 351 4050320, E-mail address: xyguo@sxicc.ac.cn (X.-Y. Guo).
}

\begin{abstract}
Carbon trees, quite different from those previously reported, have been produced by the catalytic chemical vapor deposition of toluene using ferrocene as the catalyst precursor. The influences of formation conditions such as catalyst mass, toluene flow rate, and reaction time on the tree growth and morphology have been investigated. The yield of carbon trees is greatly affected by catalyst quantity. A lower toluene flow rate $(50-100 \mathrm{ml} / \mathrm{min})$ or shorter reaction time (10-30 min) leads to trees with thinner (several microns) and filamentous branches, while a higher toluene flow rate (greater than $200 \mathrm{ml} / \mathrm{min}$ ) or longer reaction time $(60-120 \mathrm{~min})$ produces thicker (tens of microns) and spherical branches. Results suggest that the morphology of the carbon trees can be adjusted by varying the reaction conditions.
\end{abstract}

\section{Introduction}

Branched carbon structures have been found for a long time [1] and [2]. Due to their excellent properties and potential applications, branched carbon fibers and nanotubes have been extensively studied [3], [4], [5] and [6]. Baker suggested that the generation of branched carbon filament network by growing filaments onto primary fibers could create composites with unique physical, chemical, and electronic properties, and carbon fiber's common problems of weak strength in the third direction could be eliminated in the composites [3]. An approximate theory describing pull-out of fibers with tree-like structure from a matrix was developed to quantify the effects of fractal fibers [4]. The results showed that composite materials mixed with branched fibers had much more excellent mechanical properties than those mixed with straight fibers. Branched carbon fibers/nanotubes were also expected to have an application as electric conductive additive to resin or paint [5]. Recently, the electrical switching and logic functionalities of Y-branched carbon nanotubes (CNTs) were experimentally studied [6].

Branched carbon fibers and CNTs have been generated by various methods. Shi et al. prepared branched carbon nanofibers by an improved chemical vapor deposition (CVD) method using ferrocene as the catalyst precursor and benzene as the carbon source [5]. Ajayan and coworkers reported a micron-sized tree-like carbon structure produced from a flash CVD process of methane [7] and [8]. Qiu et al. synthesized branched CNTs using the arc-discharge approach from coal [9]. Xu et al. reported the growth of Y-junction CNTs using nanochannel alumina template [10]. Shih et al. described the generation of branched CNTs using microwave plasma enhanced CVD on silicon wafer [11]. Rao et al. synthesized Y-junction CNTs using Ti-doped Fe catalysts [12].

However, most of the above methods suffer either from the complicated preparation processes or the absence of controlled growth. Our research group has reported a simple method for the 
generation of centimeter-scaled multi-branched carbon structures namely "carbon trees" before [13] and [14]. The structures were produced from pyrolysis of toluene with ferrocene as the catalyst precursor, and they exhibited three-dimensionally grown dendritic and fractal structures. The carbon trees usually grew at the thermocouple end, and a growth mechanism was proposed to explain the carbon tree growth process [13]. Simultaneously, some tiny filamentous products were also found on the thermocouple pole, near to the thermocouple end. Due to their small size compared to the centimeter-scaled carbon trees, these tiny products did not attract our attention in the past. Recently, to understand the growth of carbon trees more thoroughly, the small filaments are carefully collected and studied. SEM images show that these products also have multi-branched tree-like structures. The newly found structures are different from the previously obtained carbon trees not only in the macroscopic dimension but also in the morphology. Here, we describe the generation of these smaller carbon trees. The influences of formation conditions such as catalyst mass, toluene flow rate, and reaction time on the tree growth and morphology are investigated in detail.

\section{Experimental}

The schematic of the experimental apparatus is shown in Fig. 1. The preparation details of small carbon trees are the same to those of the large trees [13] and [14]. Briefly, a horizontally placed tubular quartz reactor loaded in a tubular furnace is employed in the experiment. An aluminacoated thermocouple is put in the tube center. Toluene is used as the carbon source and is introduced into the reactor by argon bubbling at the room temperature. Simultaneously, another argon flow is used to adjust the total flux passing through the reactor. The catalyst precursor (ferrocene) placed at the low temperature part of the furnace is sublimed at about $150{ }^{\circ} \mathrm{C}$ and then is transported to the reaction region by the two argon flows. After the reaction, the black filamentous products are collected from the thermocouple pole, about 4-8 $\mathrm{cm}$ to the thermocouple end. The standard reaction conditions are as follows: reaction temperature 1150 ${ }^{\circ} \mathrm{C}$, ferrocene mass $0.1 \mathrm{~g}$, the flow rate of carrier gas (argon) $1300 \mathrm{ml} / \mathrm{min}$, the flow rate of bubbling gas (another Ar flow) through toluene $200 \mathrm{ml} / \mathrm{min}$, reaction time $1 \mathrm{~h}$.

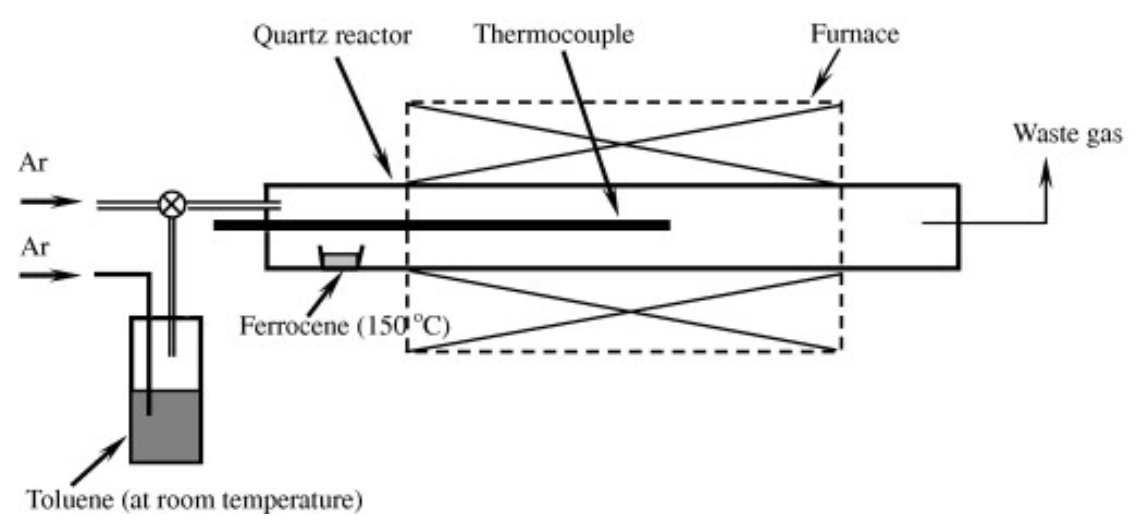

Fig. 1.Schematic of the apparatus used for preparation of the carbon trees.

To study the influence of catalyst quantity on the yield of small carbon trees, the mass of ferrocene is varied from 0 to $0.15 \mathrm{~g}$. The tree yields of different catalyst quantities are calculated by repeating the experiments under same conditions for 10 times and averaging the results. The effect of toluene flow rate on the small carbon tree growth and morphology is investigated by changing the flow rate of bubbling gas through the toluene from 25 to $400 \mathrm{ml} / \mathrm{min}$. To study the evolution process of small carbon trees, the reaction duration is varied from 10 to $120 \mathrm{~min}$ and the products obtained at different reaction times are characterized by SEM. During the investigation on the carbon tree preparation conditions, except for the above mentioned 
variations, all the other conditions are kept at the standard state. The morphologies of carbon trees are examined using a SEM (JSM-6360LV).

\section{Results and discussion}

\subsection{Formation and morphology of small carbon trees}

Fig. 2 shows the schematic of the temperature distribution in the tube reactor and the growth position of carbon trees. It has been mentioned that the large carbon trees were usually obtained at the thermocouple end (see Fig. 2 and [13] and [14]). For the small trees, at most instances they grow on the thermocouple pole, about $4-8 \mathrm{~cm}$ to the thermocouple end, as shown in Fig. 2. Fig. 3 is an optical photograph showing the macroscopic dimensions of the two kinds of carbon trees. It can be seen that the large trees usually have lengths of several centimeters, even more than 10 $\mathrm{cm}$. However, the length of small trees is only several millimeters. More differences between two kinds of trees lie in their morphology. As the SEM images shown in Fig. 4, the small trees obtained at $1150{ }^{\circ} \mathrm{C}$ have short and sphere-stacking shaped branches like coral (Fig. 4a), which is similar to the carbon trees obtained at $1000-1050{ }^{\circ} \mathrm{C}$ previously reported (see Fig. $4 \mathrm{c}$ and [14]). However, the large trees obtained at $1150{ }^{\circ} \mathrm{C}$ have long, straight, and smooth branches (see Fig. $4 \mathrm{~b}$ and references [13] and [14]).

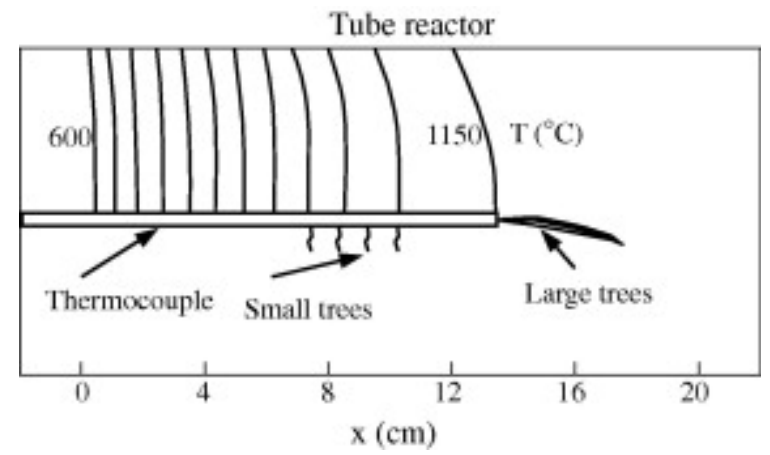

Fig. 2. Schematic of temperature distribution in the tube reactor (the interval of isothermal lines is $50{ }^{\circ} \mathrm{C}$ ) and carbon tree growth positions.

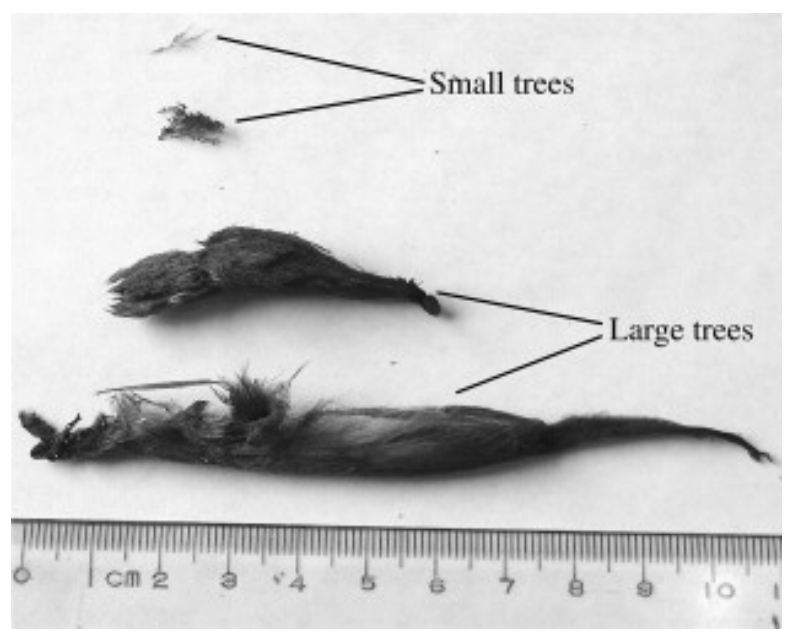

Fig. 3. Comparison of the macroscopic dimensions of large and small trees.

The growth process of the small carbon trees may be explained based on our previous postulations [13]. According to the theory of hydromechanics [15], when the Reynolds number is large enough, many gaseous vortices can be formed at the end of the thermocouple. The carbon particles produced from the toluene pyrolysis are drawn to the thermocouple end by the vortices 
and act as building blocks for generating the carbon trees. At other positions of the reactor, such as the thermocouple pole or the reactor wall, the gas flow field is not as complex as that behind the thermocouple pole. However, the carbon particles also have chances to impinge upon these positions and some of them may adhere there and then develop into nuclei for the carbon tree growth. It is found that the carbon trees on the thermocouple pole are apparently smaller than those at the thermocouple end (Fig. 3), which may be related to the difference of the gas flow fields at different positions. On the other hand, it has been pointed out in Fig. 2 that the small trees were usually obtained on the thermocouple pole where the temperature was about 1000 $1100{ }^{\circ} \mathrm{C}$. Therefore, we suggest that the temperature field on the thermocouple pole may also affect the morphology of the small carbon trees.
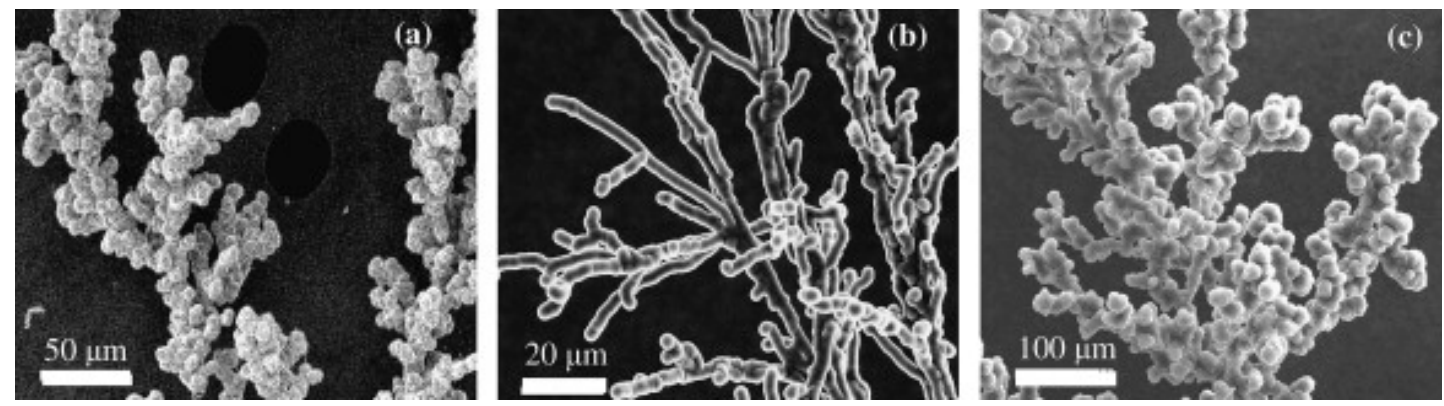

Fig. 4. SEM images of several representing carbon trees: (a) small trees obtained at $1150{ }^{\circ} \mathrm{C}$ under standard reaction conditions, (b) large trees obtained at $1150{ }^{\circ} \mathrm{C}$, and (c) carbon trees obtained at $1000{ }^{\circ} \mathrm{C}$.

\subsection{Influence of reaction conditions on the growth and morphology of small carbon trees}

\subsubsection{Influence of catalyst mass on the growth of small carbon trees}

Fig. 5 shows the effect of ferrocene mass on the growth of small carbon trees. In the absence of ferrocene, no tree-like products can be obtained. When the ferrocene mass is increased in the range of $0-0.07 \mathrm{~g}$, the tree yield can be effectively enhanced. The maximum yield is obtained with $0.07 \mathrm{~g}$ ferrocene. With the further addition of ferrocene quantity to $0.1-0.15 \mathrm{~g}$, however, the tree yield does not increase any more. The data in Fig. 5 indicate the indispensable role of ferrocene in the carbon tree growth, and the quantity of ferrocene should be appropriate for getting the maximum tree yield.

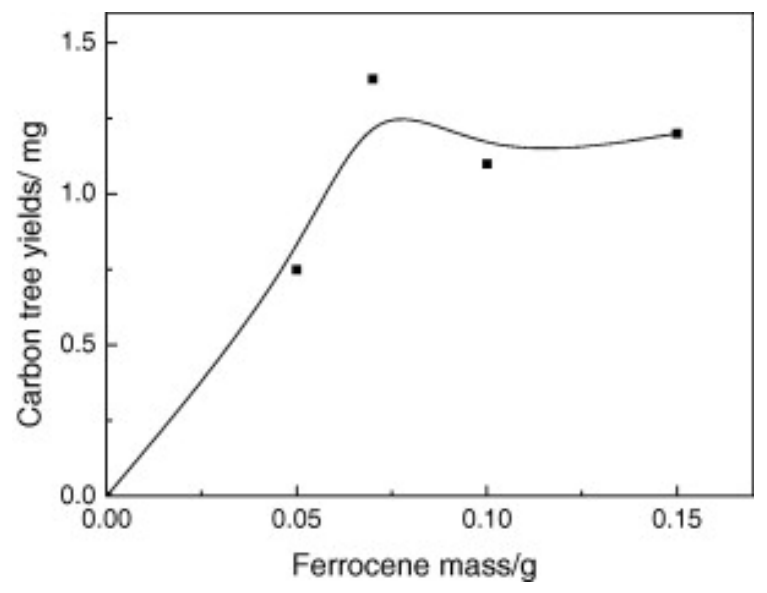

Fig. 5. Effect of ferrocene mass on the small carbon tree yield.

\subsubsection{Influence of toluene flow rate on the growth and morphology of small carbon trees}

Fig. 6 shows the SEM images of carbon trees generated at different toluene flow rates. When the flow rate of argon bubbling through toluene is $25 \mathrm{ml} / \mathrm{min}$, no tree-like product but little carbon 
black is found on the thermocouple pole. As the bubbling gas flow rate is raised to $50 \mathrm{ml} / \mathrm{min}$, some tiny filamentous products are observed on the thermocouple pole. SEM observation shows that they have branched structures (Fig. 6a). The morphology of the product obtained at 100 $\mathrm{ml} / \mathrm{min}$ bubbling gas flow rate (Fig. 6b) is similar to that at $50 \mathrm{ml} / \mathrm{min}$ gas flow rate. The tree branches under these conditions have the diameter of about 1.0-3.8 $\mu \mathrm{m}$ and show slight and filamentous morphology. However, things change greatly when the bubbling gas flow rate is raised to $200 \mathrm{ml} / \mathrm{min}$. Tree branches under this gas flow rate apparently grow thicker and show sphere-stacking pattern (Fig. 6c). When the gas flow is increased further, the tree branches continue to grow thicker and the spherical morphology no longer change.
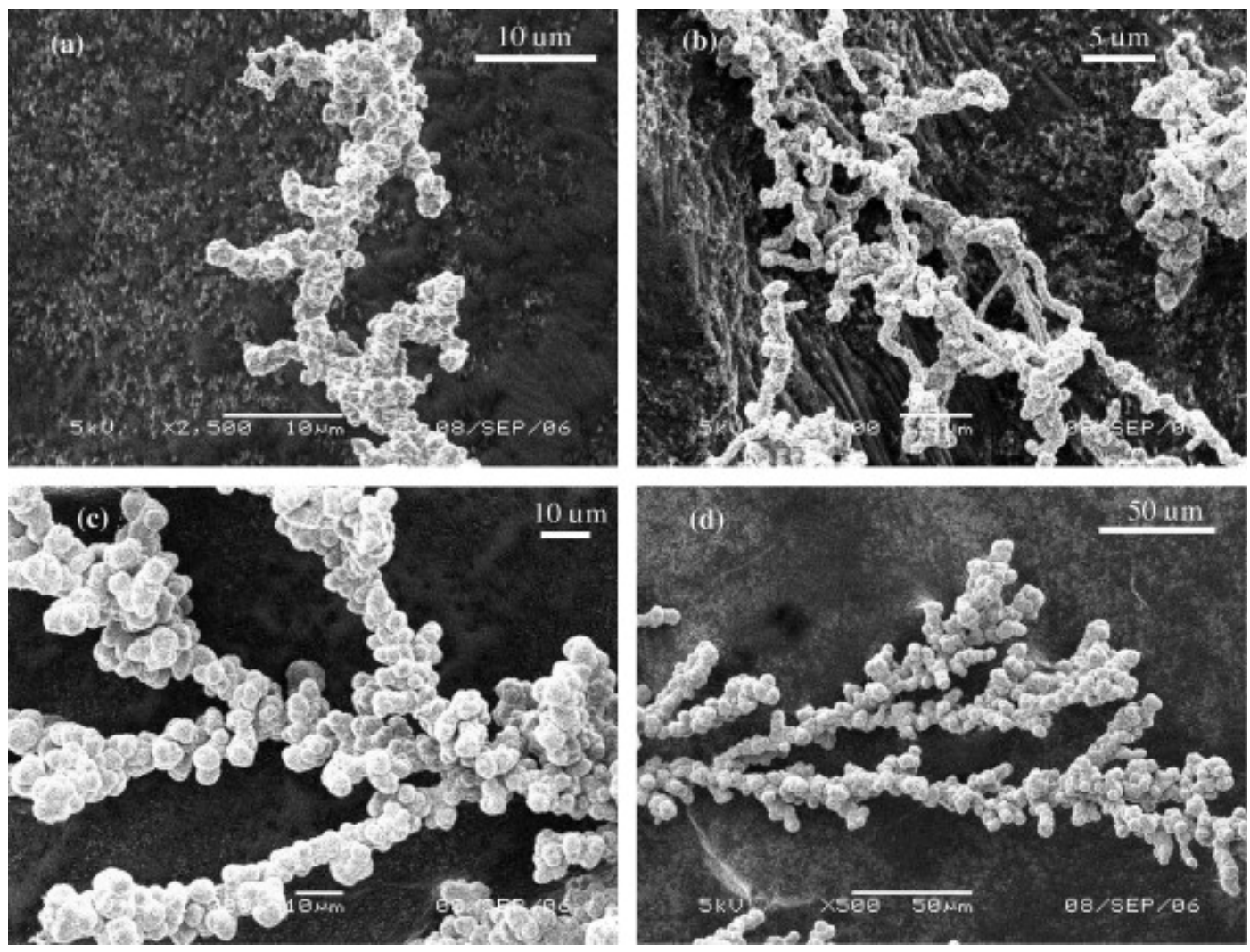

Fig. 6. SEM images of the small carbon trees obtained at different toluene flow rates: (a) $50 \mathrm{ml} / \mathrm{min}$, (b) $100 \mathrm{ml} / \mathrm{min}$, (c) $200 \mathrm{ml} / \mathrm{min}$, and (d) $400 \mathrm{ml} / \mathrm{min}$.

Above studies imply that the morphology of carbon trees is significantly influenced by the toluene flow rate. In the experiments, toluene is pyrolyzed to produce carbon, which deposits on the metal catalyst surface and perform the nucleation and generation process of carbon trees. Therefore, different toluene flow rates result in different carbon concentrations and thus lead to the variation of carbon tree generation process and growth rate, which may cause the differences in the carbon tree morphology.

\subsubsection{Carbon tree evolution processes at standard conditions}

SEM images of the carbon trees obtained at different reaction durations are shown in Fig. 7. It can be seen that the branched structures have already been formed in the initial 10 min (Fig. 7a). The average length of the trees obtained by $10 \mathrm{~min}$ reaction time is about $2 \mathrm{~mm}$ and the average diameter of the branches is about $4.7 \mu \mathrm{m}$. The trees of 20 min reaction time have an average length of about $3 \mathrm{~mm}$ and a branch diameter of about $6.7 \mu \mathrm{m}$. With the further increase of reaction time, the trees grow faster. The trees obtained by 30 min reaction time have an average length of about $5.5 \mathrm{~mm}$ and a branch diameter about $7.5 \mu \mathrm{m}$. When the reaction time is increased to $1 \mathrm{~h}$, the length of carbon trees reaches to the maximum value of about $12 \mathrm{~mm}$, and the tree 
branches change from thin, filamentous structure to thicker and sphere-stacking morphology. When the reaction time is longer than $1 \mathrm{~h}$, the lengthening growth of the trees is terminated and the branch thickening process continues.
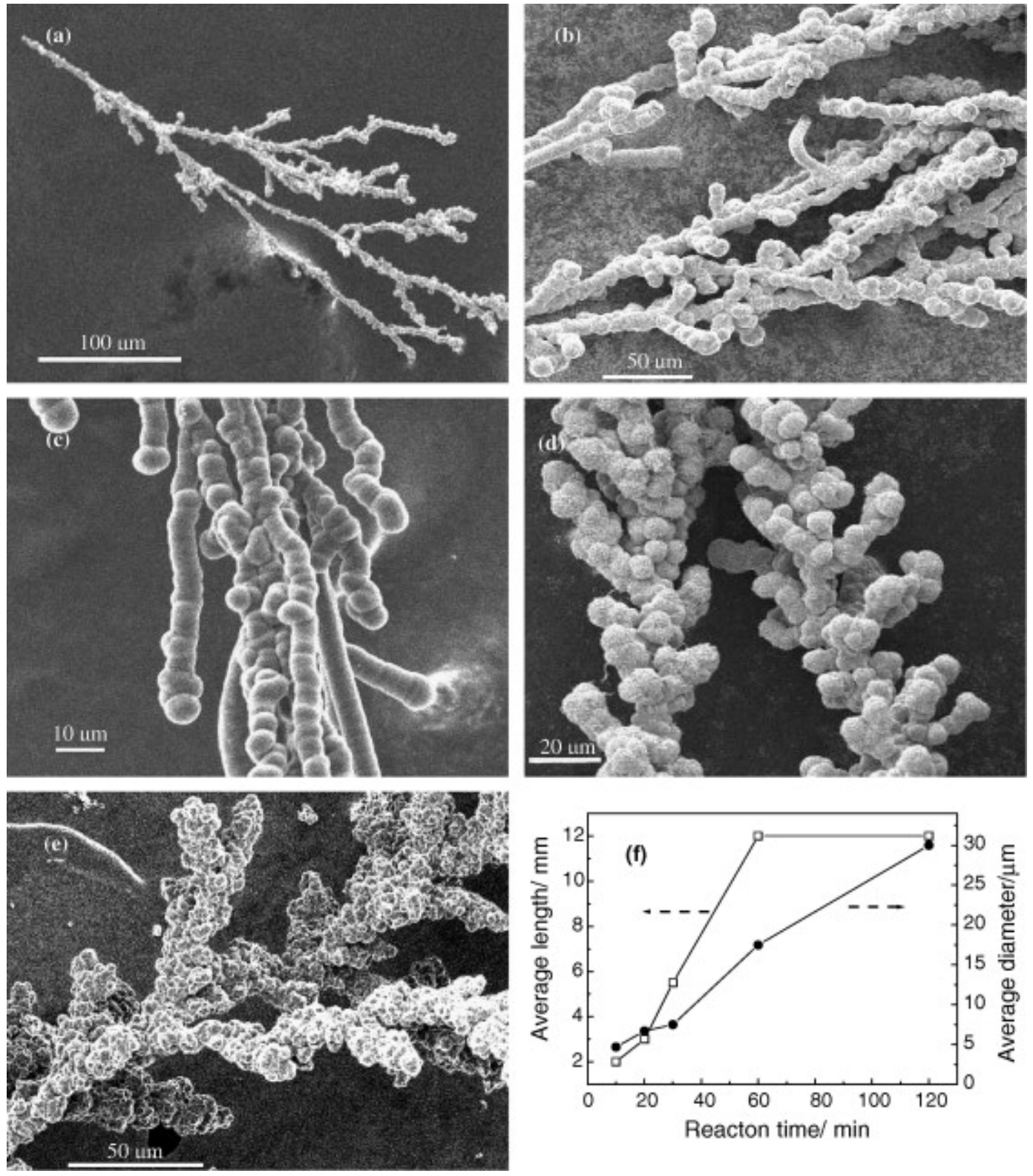

Fig. 7. Evolution of the small carbon trees. Reaction time: (a) $10 \mathrm{~min}$, (b) $20 \mathrm{~min}$, (c) $30 \mathrm{~min}$, (d) $60 \mathrm{~min}$, (e) 120 min and (f) average length and diameter of the carbon trees at different reaction times.

The variation processes of the small carbon tree morphology at different reaction durations are quite similar to that at different toluene flow rates. Lower toluene flow rate $(50-100 \mathrm{ml} / \mathrm{min})$ and shorter reaction time (10-30 $\mathrm{min})$ lead to the carbon trees with thinner and filamentous branches, while higher toluene flow rate (greater than $200 \mathrm{ml} / \mathrm{min}$ ) or longer reaction time $(60-120 \mathrm{~min}$ ) results in the carbon trees with thicker and spherical branches. These suggest that the morphology of carbon trees can be adjusted through the variation of the reaction conditions.

\section{Conclusions}

Smaller multi-branched carbon trees have been successfully prepared on the thermocouple pole in a catalytic CVD process of toluene at $1150{ }^{\circ} \mathrm{C}$ using ferrocene as the catalyst precursor. We 
suggest that it is the gas flow field and the lower temperature distribution $\left(1000-1100{ }^{\circ} \mathrm{C}\right)$ on the thermocouple pole that determines the growth process and the morphology of small carbon trees. The yield of carbon trees is greatly affected by the catalyst quantity, and the maximum yield is obtained with the ferrocene mass of $0.07 \mathrm{~g}$. The carbon trees with thinner (several microns) and filamentous branches can be prepared when the toluene flow rate is lower than $200 \mathrm{ml} / \mathrm{min}$ or the reaction time is ranged at 10-30 min. On the other hand, the trees with thicker (tens of microns) and spherical branches can be obtained when the toluene flow rate is higher than $200 \mathrm{ml} / \mathrm{min}$ or the reaction time is longer than $1 \mathrm{~h}$. These results enable us to prepare the branched carbon structures according to the desired sizes and morphologies.

\section{Acknowledgements}

The authors thank Ms. Gisela Weinberg for some SEM characterizations and Dr. Yingyong Wang for helpful discussions.

\section{References}

[1] T. Koyama, Formation of carbon fibers from benzene, Carbon 10 (6) (1972), pp. 757-758.

[2] R.T.K. Baker and P.S. Harris, The formation of filamentous carbon. In: P.L. Walker and P.A. Thrower, Editors, Chemistry and physics of carbonVol. 14, Dekker, New York (1978), pp. 83-165.

[3] R.T.K. Baker, Catalytic growth of carbon filaments, Carbon 27 (3) (1989), pp. 315-323.

[4] S. Fu, B. Zhou and C. Lung, On the pull-out of fibers with fractal-tree structure and the interference of strength and fracture toughness of composites, Smart Mater Struct 1 (2) (1992), pp. 180-185.

[5] Y.F. Shi, H.J. Quan, G.B. Zheng, H. Sano and Y. Uchiyama, Branched carbon nanofibers synthesized by an improved floating catalytic method, J Mater Sci 39 (4) (2004), pp. 1495-1497.

[6] P.R. Bandaru, C. Daraio, S. Jin and A.M. Rao, Novel electrical switching behaviour and logic in carbon nanotubes Y-junctions, Nat Mater 4 (2005), pp. 663-666.

[7] P.M. Ajayan, J.M. Nugent, R.W. Siegel, B. Wei and Ph. Kohler-Redich, Growth of carbon microtrees, Nature 404 (2000), p. 243.

[8] Y.J. Jung, B. Wei, J. Nugent and P.M. Ajayan, Controlling growth of carbon microtrees, Carbon 39 (14) (2001), pp. 2195-2201.

[9] Z. Wang, Z. Zhao and J. Qiu, Synthesis of branched carbon nanotubes from coal, Carbon 44 (7) (2006), pp. $1321-1324$.

[10] J. Li, C. Papadopoulos and J. Xu, Growing Y-Junction carbon nanotubes, Nature 402 (1999), pp. $253-254$.

[11] S.H. Tsai, C.T. Shiu, W.J. Jong and H.C. Shih, The welding of carbon nanotubes, Carbon 38 (13) (2000), pp. 1899-1902.

[12] N. Gothard, C. Daraio, J. Gaillard, R. Zidan, S. Jin and A.M. Rao, Controlled growth of Y-junction nanotubes using Ti-doped vapor catalyst, Nano Lett 4 (2) (2004), pp. 213-217.

[13] X.-Y. Guo, Macroscopic multi-branched carbon trees generated from chemical vapor deposition of toluene, Carbon 43 (5) (2005), pp. 1098-1100.

[14] H.-L. Ma, D.S. Su, A. Klein-Hoffmann, G.-Q. Jin and X.-Y. Guo, Morphologies and microstructures of treelike carbon at different reaction conditions in a CVD process, Carbon 44 (11) (2006), pp. 2254-2260.

[15] R.P. Feynman, R.B. Leighton and M. Sands, The Feynman lectures on physics II, Addison-Wesley (1964) 418 . 